\title{
HPLC DETECTION OF DEHYDROEPIANDROSTERONE IN FOOD ADDITIVES BY USING NORMAL-PHASE HPLC
}

\author{
Stanislava Ivanova ${ }^{1}$, Kalin Ivanov ${ }^{1}$, Rumen Mladenov ${ }^{1}$, Danka Obreshkova ${ }^{2}$, \\ Stefka Ivanova ${ }^{2}$, Plamen Stoyanov ${ }^{1}$ \\ ${ }^{1}$ Department Pharmacognosy and Pharmaceutical Chemistry, Faculty of Pharmacy, \\ Medical University - Plovdiv \\ ${ }^{2}$ Department of Pharmaceutical Chemistry, Faculty of Pharmacy, \\ Medical University - Sofia
}

\begin{abstract}
A normal-phase High Performance Liquid Chromatography (HPLC) method was developed for the determination of dehydroepiandrosterone (DHEA) in food supplements. We have used an HPLC 200 (Perkin Elmer, USA) with a spectrophotometric detector LC-785A (Bioanalytical systems, USA) and a thermostat (Perkin Elmer, Waltham, MA, USA). We have chosen isocratic HPLC elution, column: LiChrospher (100 DIOL 250 x $4 \mathrm{~mm} \times 5 \mu \mathrm{m}$ ), mobile phase: acetonitrile: water $=98: 2 \mathrm{v} / \mathrm{v}$, flow rate: $1 \mathrm{ml} / \mathrm{min}$. and detection at $\lambda=202$ $\mathrm{nm}$. We have found that this method allows fast and selective qualitative and quantitative determination of DHEA in pharmaceutical products.
\end{abstract}

Keyword: DHEA, HPLC, Androstenolon, Prasterone

\section{INTRODUCTION}

Dehydroepiandrosterone (DHEA), also known as Prasterone (INN) is an important endogenous steroid hormone. It functions primarily as a metabolic intermediate in the biosynthesis of androgenic and estrogenic sex steroids $(1,2)$. DHEA is a precursor of important both female and male hormones. DHEA supplementation is used to energise the body in athletes and people undergoing physical activity; to improve memory and concentration of attention; to activate the immune system; to increase testosterone levels in the body. Clinical studies have demonstrat-

Address for correspondence:

Stanislava Ivanova,

15A V. Aprilov Blvd

Faculty of Pharmacy

Medical University - Plovdiv

e-mail: stanislava_sl@abv.bg

Received: May 17, 2016

Accepted: June 23, 2016 ed that the use of DHEA leads to improved mood, increased resistance to stress, improved sleep quality, as well as benefit male and female individuals in premenopausal and postmenstrual age $(3,4,5,6,16,17)$. Legislative frameworks relating to DHEA worldwide are very controversial: some countries even banned imports of DHEA products, in others it may be granted only on prescription for medical purposes and is a controlled substance; also there are countries in which DHEA is sold and distributed freely as a dietary supplement. In Bulgaria, DHEA is available as a dietary supplement. The procedure for registration, sale and control is extremely liberal. DHEA products are sold as food supplements and can be purchased at pharmacies, drugstores, grocery stores and via the Internet. DHEA is a prohibited substance by the World Anti-Doping Agency. Gas chromatography with mass spectrometry and liquid chromatography with mass spectrometry are used for the detection of DHEA and its metabolites in biological samples $(7,8,9,10)$. The High Performance Liquid Chroma- 
Stanislava Ivanova, Kalin Ivanov, Rumen Mladenov et al.

tography (HPLC) method is most commonly used to determine DHEA in food additives $(11,12,13,14,15)$. The reversed-phase HPLC is most commonly used option, described in the scientific literature, for the chromatographic determination of DHEA. The hydrophobic properties of DHEA also allow the application of a normal phase liquid chromatography.

\section{MATERIALS AND METHODS}

Materials

I) Reference standard: trans-Dehydroandrosterone $\geq 99 \%$ (Sigma-Aldrich)

II) Reagents with analytical grade quality: acetonitrile for HPLC (Sigma Aldrich), distilled water.

\section{Methods:}

Normal-phase HPLC.

I) Instrumentation:

HPLC 200 (Perkin Elmer, USA) with: spectrophotometric detector LC-785A (Bioanalytical systems, USA); thermostat (Perkin Elmer, Waltham, MA, USA); ultrasonic bath (Branson Wilmington, NC, USA); apparatus for ultrapure water: "Milli-Q", "Milipore" (Bedford, MA, USA) and "Elga" (VWR International, Randor, PA, USA).

II) Chromatographic conditions: isocratic HPLC elution at: stationary phase: column: LiChrospher (100 DIOL 250 x $4 \mathrm{~mm} \times 5 \mu \mathrm{m}$ ), mobile phase: acetonitrile: water $=98: 2 \mathrm{v} / \mathrm{v}$, flow rate: $1 \mathrm{ml} / \mathrm{min}$., detection at $\lambda=202 \mathrm{~nm}$.

\section{III) Preparation of solutions of substances:}

1. Preparation of stock standard solution of DHEA. An accurately weighed quantity (4.1 mg) of reference substance Dehydroandrosterone was dissolved in $20 \mathrm{ml}$ acetonitrile under sonication in ultrasonic bath. After dilution with acetonitrile in a volumetric flask of $50.0 \mathrm{ml}$, a solution with a concentration of Dehydroandrosterone $82 \mu \mathrm{g} / \mathrm{ml}$ was obtained. The solution is stable for more than a week under refrigeration $\left(4 \div 8^{\circ} \mathrm{C}\right)$.

2. Preparation of a solution of sample 1 . An amount equivalent to $28.7 \mathrm{mg}$ DHEA was weighed from crushed tablet mass, $20 \mathrm{ml}$ of acetonitrile were added and the sample was sonicated $5 \mathrm{~min}$. in an ultrasonic bath with stirring periodically. The resulting suspension was diluted in a volumetric flask $50.0 \mathrm{ml}$ with acetonitrile. The solution was filtered through a $0.45 \mu \mathrm{m}$ membrane filter and analysed by the described HPLC method.

3. Preparation of a solution of sample 2 . An amount equivalent to $18 \mathrm{mg}$ DHEA was weighed from crushed tablet mass, $20 \mathrm{ml}$ of acetonitrile were added and the sample was sonicated $5 \mathrm{~min}$. in an ultrasonic bath, stirring periodically. The resulting suspension was diluted in a volumetric flask $50.0 \mathrm{ml}$ with acetonitrile. The solution was filtered through a $0.45 \mu \mathrm{m}$ membrane filter and analysed by the described HPLC method.

\section{RESULTS AND DISCUSSION:}

The most commonly used method to determine DHEA is the reversed-phase HPLC. We have found that the hydrophobic properties of DHEA allow the use of normal-phase HPLC. We have tried some different types of chromatographic separation to find the most appropriate one for the determination of DHEA in food supplements. Figures 1, 2 and 3 show chromatograms of standard substance of DHEA, obtained with different types of chromatographic separation (using different types of chromatographic columns). We have found that the normal-phase HPLC shows higher selectivity, therefore we have chosen this method for determination of DHEA in the samples. The use of a spectrophotometric detector in this method was a bit difficult. The spectrophotometric detection is hindered by the lack of intense optical absorption of DHEA in the operating range of the wavelength (220 nm and above). The intense optical absorption of DHEA is displaced in the far ultraviolet region - $190-205 \mathrm{~nm}$. To accomplish a high sensitivity, the detection was performed at $202 \mathrm{~nm}$. For determination of DHEA we have used a mobile phase containing 98\% acetonitrile, especially clean ("Gradient grade"), and $2 \%$ ultrapure water. Flow rate: $1 \mathrm{ml} / \mathrm{min}$. Under these conditions, we built a standard schedule for DHEA by obtaining chromatograms of a series of standard solutions with a concentration of $0.8 \mu \mathrm{g} / \mathrm{ml}$ to $80 \mu \mathrm{g} / \mathrm{ml}$, from which the linear range and sensitivity in normal-phase chromatographic determination of DHEA with spectrophotometric detection at $202 \mathrm{~nm}$ was determined (Figure 4). Figures 6 and 7 represent the chromatograms of the analyzed samples, obtained by using normal-phase HPLC. 
Hplc Detection of Dehydroepiandrosterone in Food Additives by Using Normal-Phase HPLC

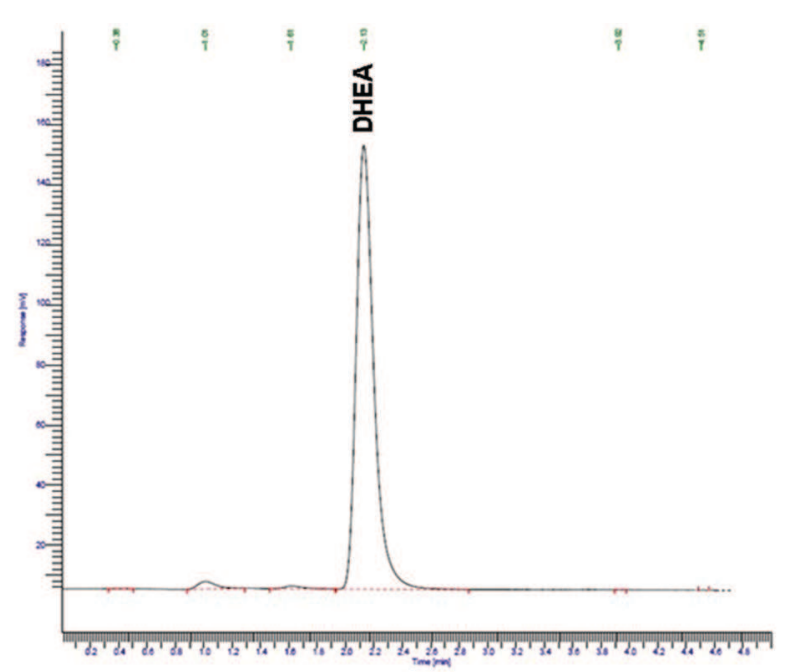

Figure 1. Chromatogram of a standard solution of DHEA obtained by reverse-phase chromatography on a C18 column with a modified silica (Nova Pack C18, $150 \times 4.6 \mathrm{~mm}$ $5 \mathrm{um})$

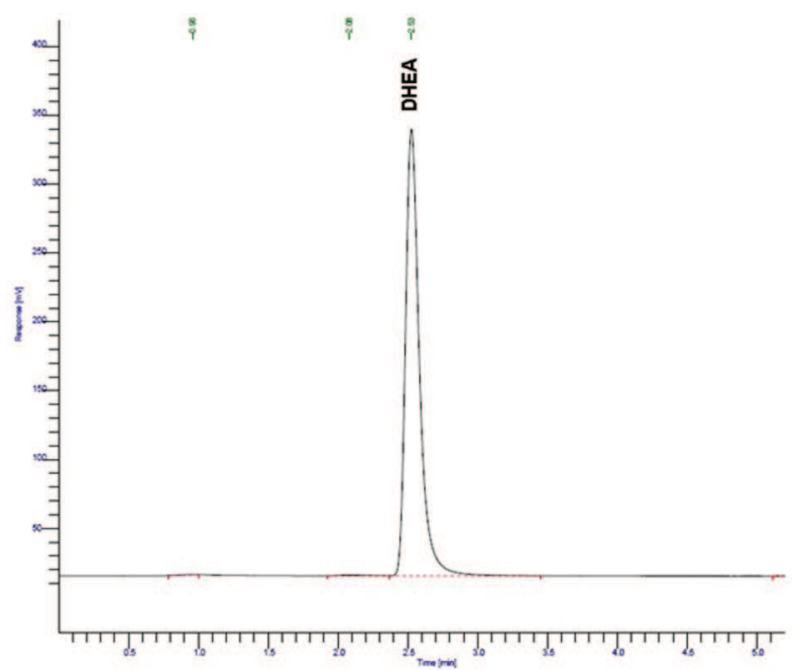

Figure 2. Chromatogram of a standard solution of DHEA obtained by reverse-phase chromatography on a column of C18-modified organic vehicle (Gemini-NX C18, 150 $m m \times 2 \mathrm{~mm} 3 \mu \mathrm{m})$

We have validated the described method on the following validation parameters: linearity, limit of detection (LOD) and repeatability.

We built a standard graphic for DHEA by obtaining chromatograms of a series of standard solutions with a concentration from $0.8 \mu \mathrm{g} / \mathrm{ml}$ to $80 \mu \mathrm{g} /$ $\mathrm{ml}$. We determined the linear range though normalphase chromatographic determination of DHEA with spectrophotometric detection at $202 \mathrm{~nm}$ (Fig. 4). In the concentration range $0.8 \div 80 \mu \mathrm{g} / \mathrm{ml}$ the stan-

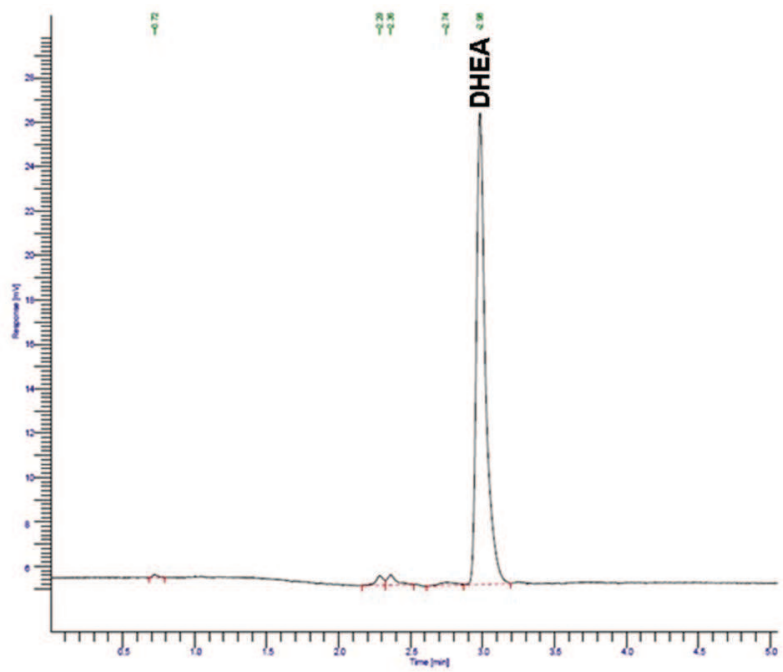

Figure 3. Chromatogram of a standard solution of DHEA obtained by normal-phase chromatography, column DIOL, $250 \times 4 \mathrm{~mm}, 10 \mu \mathrm{m}$

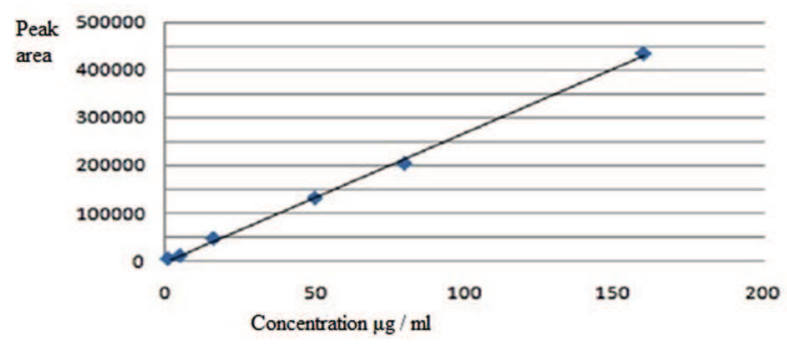

Figure 4. Dependence of the surface of the chromatographic peak on the concentration of DHEA, constructed by the introduction of $5 \mu \mathrm{l}$ standard solutions with concentrations of $0.8,4.8,16,50,82$ and $164 \mu \mathrm{g} / \mathrm{ml}$

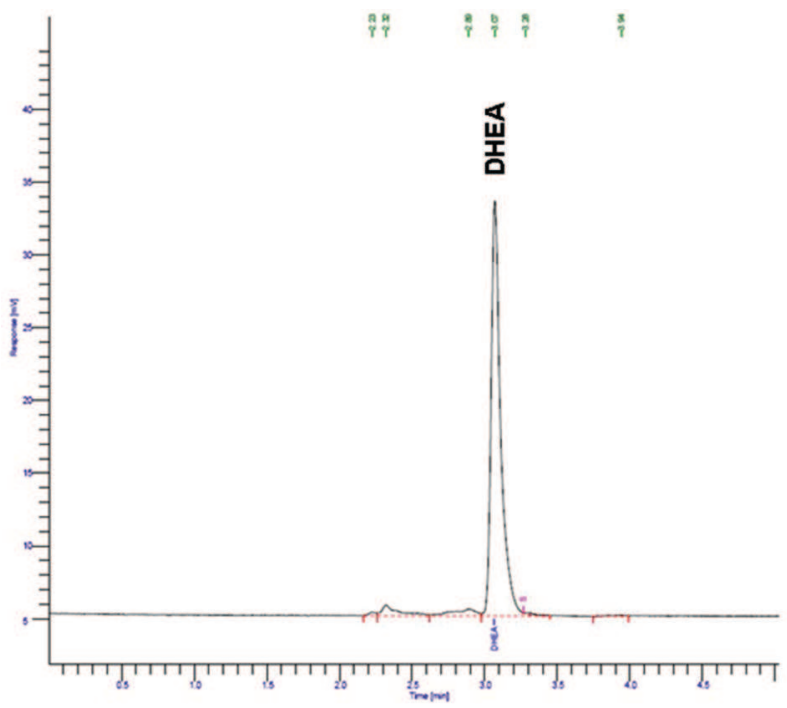

Figure 5. Chromatogram of $5 \mu \mathrm{l}$ standard solution of DHEA with concentration $0.8 \mu \mathrm{g} / \mathrm{ml}$ 


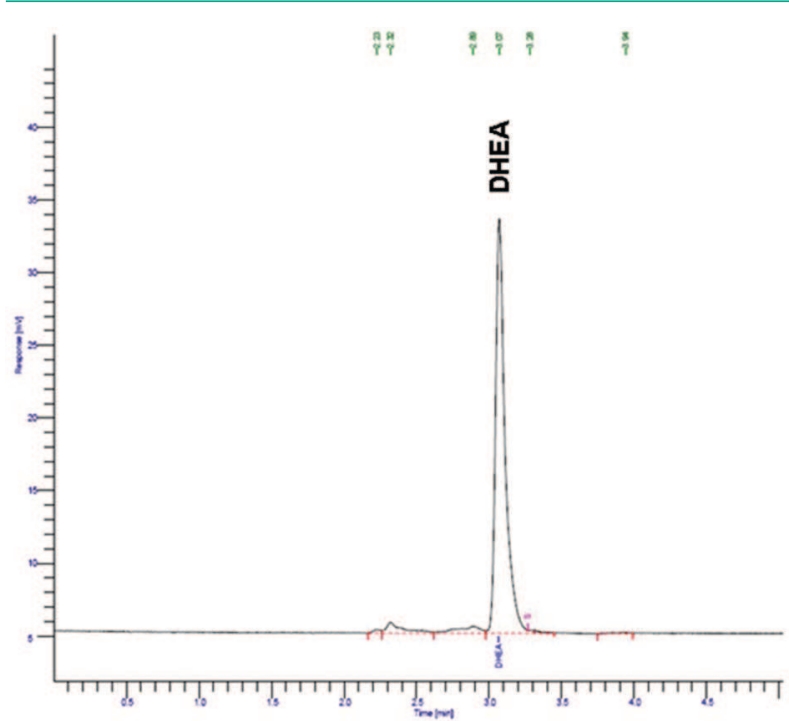

Figure 6. Chromatogram of the analyzed sample 1

dard schedule is linear with a correlation coefficient $\mathrm{R}=0.9989$ equation $\mathrm{y}=8544.76+2375.04$

The LOD was established by the chromatograms of solutions of DHEA with decreasing concentration, until the height of the chromatographic peak became commensurable with the noise of the detector. Figure 5 shows a chromatogram of the standard

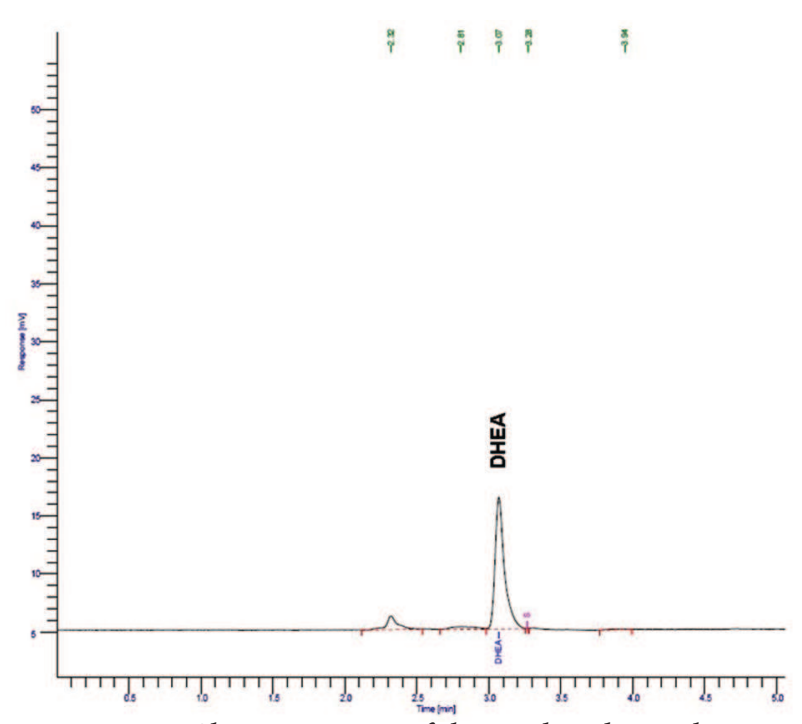

Figure 7. Chromatogram of the analyzed sample 2

solution with a concentration of DHEA $0.8 \mu \mathrm{g} / \mathrm{ml}(4$ ng introduced amount of DHEA), which was calculated from the amount administered, wherein the peak of DHEA is 3 times the noise: 2 ng as a limit of detection. The repeatability of the method was established by a tenfold input of $10 \mu \mathrm{l}$ of solution of sample 1 in $50 \mathrm{ml}$ of acetonitrile in the apparatus for analysis and measurement of the peak area of DHEA. We

Table 1. Total content of DHEA in the analyzed food supplements

\begin{tabular}{lccc} 
Sample & $\begin{array}{c}\text { DHEA content in 1 } \\
\text { capsule (declared on the } \\
\text { label of the product) }\end{array}$ & $\begin{array}{c}\text { Origin of the } \\
\text { manufacturer }\end{array}$ & $\begin{array}{c}\text { Content of DHEA in 1 } \\
\text { capsule (results of the } \\
\text { analysis) }\end{array}$ \\
Sample 1 & $50 \mathrm{mg}$ & Bulgaria & $47 \mathrm{mg} \pm 5 \mu \mathrm{g}$ \\
Sample 2 & $50 \mathrm{mg}$ & USA & $28 \mathrm{mg} \pm 5 \mu \mathrm{g}$ \\
\hline
\end{tabular}

Table 2. Repeatability of the normal-phase HPLC method for determination of DHEA in food supplements

\begin{tabular}{lc|c|c|}
\hline Measurement No. & Area & Average value & R \\
1 & 128318 & & \\
2 & 131187 & & \\
3 & 130306 & 129396 & 1306 \\
4 & 129936 & & \\
5 & 125633 & & \\
6 & 128836 & & \\
7 & 129044 & & \\
8 & 129891 & & \\
9 & 130643 & & \\
10 & 130165 & & \\
\hline
\end{tabular}


Hplc Detection of Dehydroepiandrosterone in Food Additives by Using Normal-Phase HPLC

have calculated the average peak area, the standard deviation $\sigma$ and the relative standard deviation RSD. The data is presented in Table 2 .

\section{CONCLUSION}

The interest in food supplements and their consumption is growing. This requires stronger measures for quality control of the dietary supplements. DHEA supplementation is commonly used in sports because of its high performance-enhancing potential. In this work we have developed a normal-phase HPLC method for detection and quality control of food additives containing DHEA. We have found that the normal-phase HPLC method for determination of DHEA is better than the reversed-phase HPLC because it provides higher selectivity and allows successful and quick separation of DHEA from the accompanying non-polar impurities. We have found that normal-phase HPLC is faster than reverse phase HPLC when analyze DHEA products. We have validated the described method on the following validation parameters: linearity, limit of detection (LOD) and repeatability to confirm that the procedure employed for a specific test is suitable for its intended use.

\section{Acknowledgements}

This work was supported by Medical University Plovdiv-project: DP 13/2015.

\section{REFERENCES}

1. Mo Q, Lu S, Simon N, Dehydroepiandrosterone and its metabolites: differential effects on androgen receptor trafficking and transcriptional activity". J. Steroid Biochem. Mol. Biol. 99 (1): 50-8.

2. Thomas Scott, Concise Encyclopedia Biology, published by Walter de Gruyter, 1996, p. 49.

3. Bloch M, Schmidt P, Danaceau M, Adams L, Rubinow D, Dehydroepiandrosterone treatment of midlife dysthymia, Biol Psychiatry. 1999 Jun 15; 45(12):1533-41.

4. Wolkowitz O, Reus V, Keebler A, Nelson N, Friedland M, Brizendine L, Roberts E, Double- blind treatment of major depression with dehydroepiandrosterone. Am J Psychiatry 1999;156:646-649.

5. Schmidt P, Daly R, Bloch M, Smith M, Danaceau M, StClair LS, Murphy J, Haq N, Rubinow D, Dehydroepiandrosterone monotherapy in midlife-onset major and minor depression. Arch Gen Psychiatry 2005; 62:154-62.
6. Barnhart K, Freeman E, Grisso J, Rader D, Sammel M, Kapoor S, Nestler J,The effect of dehydroepiandrosterone supplementation to symptomatic perimenopausal women on serum endocrine profiles, lipid parameters, and health-related quality of life.J Clin Endocrinol Metab 1999;84:3896-3902

7. Black $\mathrm{T}$, Does the Ban on Drugs in Sport Improve Societal Welfare, International Review for the Sociology of Sport December 1996 vol. 31 no. 4367-381, doi: $10.1177 / 101269029603100402$

8. Mareck U, Geyer H, Opfermann G, Thevis M, Schänzer W. "Factors influencing the steroid profile in doping control analysis". J Mass Spectrom, July 2008; 43(7): 877- 91.doi:10.1002/jms.1457. PMID 18570179.

9. Fragkaki A, Angelis Y, Tsantili-Kakoulidou A, Koupparis M, Georgakopoulos C ,'Schemes of metabolic patterns of anabolic androgenic steroids for the estimation of metabolites of designer steroids in human urine", J. Steroid Biochem. Mol. Biol. 115(12): 44-61. doi:10.1016/j.jsbmb.2009.02.016. PMID 19429460 .

10. Blackledge $\mathrm{R}, \mathrm{Bad}$ science: the instrumental data in the Floyd Landis case, Clin. Chim. Acta, 406(1-2): 8-13. doi:10.1016/j.cca.2009.05.016.PMID 19465014

11. Parr K, Geyer H, Reinhart U, Schänzer W, Analytical strategies for the detection of non- labelled anabolic androgenic steroids in nutritional supplements, 2004; vol.21, issue 7, pages 632- 640

12. Green G, Gary A, Catlin D, Don H, Starcevic B, Analysis of Over-the-Counter Dietary Supplements, Clinical Journal of Sport Medicine: October, 2001; 11(4): 254-259.

13. Baume N, Mahler N, Kamber M, Mangin P, Saugy M, Research of stimulants and anabolic steroids in dietary supplements, Scandinavian Journal of Medicine \& Science in Sports,l 16 (1), 2006

14. Thompson R, Carlson M, Thompson R, Carlson M, Liquid chromatographic determination of Dehydroepiandrosterone (DHEA) in dietary supplement products J AOAC 2000; 83(4): 847-857.

15. Kushnir M, Blamires T, Rockwood A, Roberts W, Yue B, Erdogan E, Bunker A, Meikle A, Liquid chromatography - tandem mass spectrometry assay for Androstenedione, Dehydroepiandrosterone, and Testosterone with pediatric and adult reference intervals. Clin Chem 2010; 56(7): 1138-1147.

16. Morales A, Nolan J, Nelson J, Yen S. Effects of replacement dose of dehydroepiandrosterone in men 
and women of advancing age, J Clin Endocrinol Metab 1994;78:1360-1367.

17. Wolf $O$, Neumann $O$, Hellhammer D, Geiben A, Strasburger C, Dressendorfer R, Pirke K, Kirschbaum C, Effects of a two-week physiological dehydroepiandrosterone substitution on cognitive performance and well-being in healthy elderly women and men. J Clin Endocrinol Metab, 1997; 82:2363-2367. 